\title{
Aseptic subcutaneous inflammation presenting as late onset back pain after uneventful epidural anesthesia
}

\author{
Pradipta Bhakta ${ }^{1}$, Brian O’Brien ${ }^{2}$, and John Richard McNamara ${ }^{2}$ \\ Department of Anesthesia and Intensive Care, ${ }^{1}$ University Hospital Limerick, Dooradoyle, Limerick, ${ }^{2}$ Cork \\ University Hospital, Cork, Ireland
}

We encountered a case of aseptic subcutaneous inflammation following epidural anesthesia (EA), which we would like to share with the journal.

A healthy woman (26 years of age; $\mathrm{G}_{1} \mathrm{P}_{0}$ ) was admitted in active labor following uneventful pregnancy. She sought EA for labor pain. Antiseptic cleaning was performed using a chlorhexidine stick, and the target area was draped aseptically. After allowing an adequate time to dry, the skin and underlying subcutaneous tissues at the target needle-entry site paramedian to the $\mathrm{L}_{3-4}$ intervertebral space were infiltrated using $2 \%$ lidocaine. An 18-gauge epidural set was inserted in the epidural space to locate it using the loss of resistance to saline technique. The epidural space was uneventfully identified at a depth of $5 \mathrm{~cm}$ on the first attempt. Subsequently, the epidural catheter was threaded, and $5 \mathrm{~cm}$ of the epidural catheter was retained in the epidural space. After a negative result by the test dose, a loading dose of levobupivacaine was administered. Subsequently, an epidural infusion was started based on our institutional protocol. The patient had instant pain relief and remained comfortable throughout.

Ultimately, a caesarean section was required because of the failure to progress, and it was successfully performed using an epidural "top-up." At the end of the surgery, the epidural cath-

Corresponding author: Pradipta Bhakta., M.D., MNAMS, FCAI, EDRA Department of Anesthesia and Intensive Care, University Hospital Limerick, St Nessan's Road, Dooradoyle, Limerick V94 F858, Ireland Tel: +353-894137596

Email: bhaktadr@hotmail.com

ORCID: https://orcid.org/0000-0002-6101-396X

Received: May 4, 2019.

Accepted: May 16, 2019.

Korean J Anesthesiol 2019 October 72(5): 508-509 https://doi.org/10.4097/kja.19187 eter was removed, and a sterile dressing was applied. The total duration of epidural catheter insertion was about 4.5 hours. She received standard antibiotic prophylaxis and postoperative care. Her recovery was uneventful, and she was discharged after 2 days.

She returned on the 7 th postoperative day with new-onset atypical back pain without a clear dermatomal pattern. She complained of exquisite pain at the needle-entry site radiating to the mid-thoracic region, contrary to a downward radiation, without any radicular involvement. She did not have fever, headache, or signs of meningism, except slight erythema at the needle-entry site. Her C-reactive protein (CRP) level and white blood cell count remained normal. Her neurological examination was unremarkable.

She was treated conservatively with analgesics, antibiotics, and physiotherapy. As severe pain persisted, interfering with childcare, neurology consultation was arranged, which did not reveal additional information. Magnetic resonance imaging (MRI) revealed inflammation of the subcutaneous tissues overlying the $\mathrm{L}_{1-5}$ vertebrae (Fig. 1). As there was no evidence of drainable fluid or hematoma, no further intervention was advocated other than continuing the conservative management. Her pain reduced steadily, and she recovered fully after 5 days.

Infective complications after EA can occur because of microbial infection during the procedure, through the needle-puncture site, or seeding of microorganisms from the blood after the traumatic procedure [1]. Non-infectious complications in and outside the neuraxis are also reported after EA [2,3]. Chlorhexidine, which is used for skin asepsis, is cytotoxic and neurotoxic $[4,5]$, but chlorhexidine-induced aseptic inflammation of subcutaneous tissues outside the neuraxis presenting as differential diagnosis after uneventful EA has not been reported. The atypical clinical presentation and MRI findings baffled us. Lack of signs

(c) This is an open-access article distributed under the terms of the Creative Commons Attribution Non-Commercial License (http://creativecommons.org/ licenses/by-nc/4.0/), which permits unrestricted non-commercial use, distribution, and reproduction in any medium, provided the original work is properly cited. 


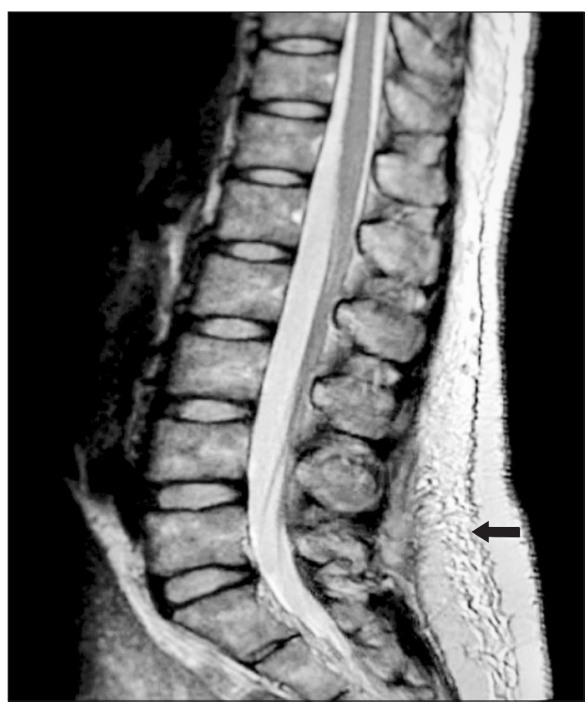

Fig. 1. Magnetic resonance imaging shows inflammation in the deep subcutaneous tissues, which are superficial to the paraspinal musculature in the midline, overlying the $\mathrm{L}_{1-5}$ vertebrae. The arrow is pointing to the area of inflammation.

of infection (fever, leukocytosis, raised CRP) or drainable fluid excluded the diagnosis of infection. The only positive finding was erythema at the needle-entry site and MRI suggestive of possible inflammation. After multidisciplinary discussions, we suspected aseptic inflammation caused by inadvertent entry of cytotoxic chlorhexidine as the most probable diagnosis. Chlorhexidine may not have completely dried before administering EA. This probably led to the entry of cytotoxic chlorhexidine causing tissue inflammation. Our assumption was proven by uneventful recovery of the complication using conservative management.

Non-infective subcutaneous inflammation outside the neuraxis presenting as late-onset atypical back pain has not been reported previously. Therefore, we would like to create awareness among fellow practitioners of this atypical presentation as a potential differential diagnosis and to reassure them of its uneventful resolution.

\section{Conflicts of Interest}

No potential conflict of interest relevant to this article was reported.

\section{Author Contributions}

Pradipta Bhakta (Conceptualization; Data curation; Methodology; Supervision; Writing-original draft; Writing-review \& editing)

Brian O’Brien (Conceptualization; Methodology; Writing-review \& editing)

John Richard McNamara (Conceptualization; Data curation; Writing-review \& editing)

\section{ORCID}

Pradipta Bhakta, https://orcid.org/0000-0002-6101-396X Brian O’Brien, https://orcid.org/0000-0002-9004-8950

John Richard McNamara, https://orcid.org/0000-0002-8242-6835

\section{References}

1. Horlocker TT, Wedel DJ. Infectious complications of regional anesthesia. Best Pract Res Clin Anaesthesiol 2008; 22: 451-75.

2. Killeen T, Kamat A, Walsh D, Parker A, Aliashkevich A. Severe adhesive arachnoiditis resulting in progressive paraplegia following obstetric spinal anaesthesia: a case report and review. Anaesthesia 2012; 67: 1386-94.

3. Raj V, Foy J. Paraspinal abscess associated with epidural in labour. Anaesth Intensive Care 1998; 26: 424-6.

4. Giannelli M, Chellini F, Margheri M, Tonelli P, Tani A. Effect of chlorhexidine digluconate on different cell types: a molecular and ultrastructural investigation. Toxicol In Vitro 2008; 22: 308-17.

5. Bogod D. The sting in the tail: antiseptics and the neuraxis revisited. Anaesthesia 2012; 67: 1305-9. 